\title{
Study on the residual stress relaxation in girth-welded steel pipes under bending load using diffraction methods
}

\author{
Nico Hempel ${ }^{\mathrm{a}, 1,{ }^{*}}$, Jeffrey R. Bunn ${ }^{\mathrm{b}, 2}$, Thomas Nitschke-Pagel ${ }^{\mathrm{a}, 3}$, E. Andrew Payzant ${ }^{\mathrm{b}, 4}$, Klaus Dilger ${ }^{\mathrm{a}, 5}$
}

\begin{abstract}
This research is dedicated to the experimental investigation of the residual stress relaxation in girthwelded pipes due to quasi-static bending loads. Ferritic-pearlitic steel pipes are welded with two passes, resulting in a characteristic residual stress state with high tensile residual stresses at the weld root. Four-point bending is applied to generate axial load stress causing changes in the residual stress state. These are determined both on the outer and inner surfaces of the pipes, as well as in the pipe wall, using X-ray and neutron diffraction. Focusing on the effect of tensile load stress, it is revealed that not only the tensile residual stresses are reduced due to exceeding the yield stress, but also the compressive residual stresses for equilibrium reasons. Furthermore, residual stress relaxation occurs both parallel and perpendicular to the applied load stress.
\end{abstract}

Keywords: X-ray diffraction; neutron scattering; steel; welding; residual stresses

\section{Introduction}

The residual stress effect on the fatigue behavior of welded steel components has not been quantified sufficiently yet. Current fatigue design standards and recommendations, like the ones given by the International Institute of Welding (IIW) [1], are based on the assumption of yield strength magnitude tensile residual stresses if the actual residual stress state is unknown. This postulate reflects uncertainties about the initial residual stress state after welding, which may depend on numerous parameters, as well as about the possible relaxation of residual stresses. The latter can occur as a result of different effects, such as annealing [2] or the loss of material containing residual stresses due to corrosion [3]. The most important effect with regard to the fatigue behavior, however, is the interaction of residual and load stresses, which may lead to local plastic deformation when the static or cyclic yield strength is exceeded, thus reducing the residual stresses. An overview about relaxation of residual stresses resulting from different manufacturing processes and their influence on the fatigue behavior is given in [4]. According to a model by Vöhringer [2], static and cyclic effects can occur separately or in combined form. In welded joints, significant residual stress relaxation is often observed during the first load cycle, followed by only small changes during further cycling [5-11] or no changes at all [12,13], as long as no fatigue crack is present.

It is obvious that information about the amount of residual stresses remaining in a component after relaxation, thus acting equivalent to a mean stress, is highly desirable. Since measurements are costly and provide only punctual information, great efforts are made in the area of numerical welding simulation. However, differences between numerical and experimental results, which are often observed as e.g. in a recent round robin organized by the IIW [14], show the need of further research in this area. While the current study is dedicated to the experimental characterization of residual stress relaxation in girth-welded steel pipes, it will serve as a reference for numerical computations of the residual stress state both after welding and after subsequent loading. Due to the fact that relaxation in welded joints is mainly observed in the first load cycle [4-13], this study will focus on the effects of quasi-static one-time loading. The experimental investigation of residual stress relaxation due to cyclic loading and of the fatigue performance of the pipe welds, as well as the results of the numerical computations, will be matter of future work.

The residual stress state in girth-welded pipes differs significantly from the one observed in plates. It has been shown that the pipe geometry and the heat input are the governing factors for the residual stress development $[15,16]$, apart from material parameters. The characterization of the welding residual stresses in the pipe welds analyzed in the current paper has already been carried out by the 
authors [17-19], using mainly X-ray and neutron diffraction. It was found that the circumferential contraction of the weld and the highly heated areas in its vicinity during cooling is constrained by the adjacent material, thus causing tensile hoop residual stress in the former and compressive hoop residual stress in the latter areas. Due to the self-constraining tubular geometry, the contraction of the weld also leads to necking of the pipe and thereby to pipe wall bending, which accounts for characteristic axial residual stresses, being highly compressive near the weld toe and tensile at the weld root. Since both spots are potential crack initiation sites due to the notch effect, residual stress relaxation is of special interest at these locations.

\section{Experimental work}

\section{General remarks}

In order to investigate the residual stress relaxation under load, the residual stresses must be analyzed both before and after loading. Ideally, the measurements would be taken on the same samples to study the residual stress evolution as accurately as possible. However, this was only possible for the X-ray diffraction measurements on the outer surface of the pipes. For the measurements on the inner surface, as well as for the neutron diffraction measurements, different samples were used to study the residual stresses in the two states. Nevertheless, it is expected that this fact does not affect the results significantly, as extensive analyses had shown that the scatter of the residual stresses after welding is rather small in different nominally identical samples.

\section{Sample preparation}

Pipes of the ferritic-pearlitic structural steel $\mathrm{S} 355 \mathrm{~J} 2 \mathrm{H}+\mathrm{N}$ were used in this study. The chemical composition of the steel was $0.190 \mathrm{C}, 0.266 \mathrm{Si}, 1.131 \mathrm{Mn}, 0.0092 \mathrm{P}$ and $0.0067 \mathrm{~S}$ in mass\% with a balance of $\mathrm{Fe}$, resulting in about 3 mass $\%$ cementite. According to tensile tests, the upper yield stress of the base material is $355 \mathrm{MPa}$; its nominal stress-strain curve is shown in Figure 1. The tubular specimens were machined on the inner and outer surface in order to remove geometrical imperfections, resulting in an outer diameter of $100.5 \mathrm{~mm}$ and a wall thickness of $7.75 \mathrm{~mm}$. Two different types of samples were prepared: Relatively short pipes of $200 \mathrm{~mm}$ length were mainly used for the residual stress analysis in the as-welded state, whereas samples with a total length of $550 \mathrm{~mm}$ served for investigations under load. While the former were made from one piece with a v-shaped groove being introduced at half-length as a weld preparation, see $[17,18]$ for details, the latter consist of two halves as shown in Figure 2 . Before welding, all pipes were stress relieved thermally at $600{ }^{\circ} \mathrm{C}$ for 30 minutes and cooled uniformly at about $1^{\circ} \mathrm{C} / \mathrm{min}$.

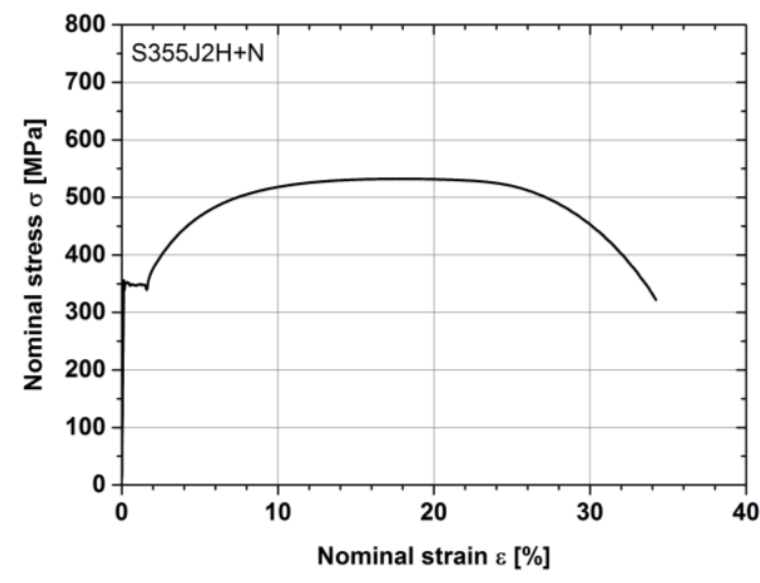

Fig. 1 Nominal stress-strain curve of the base material

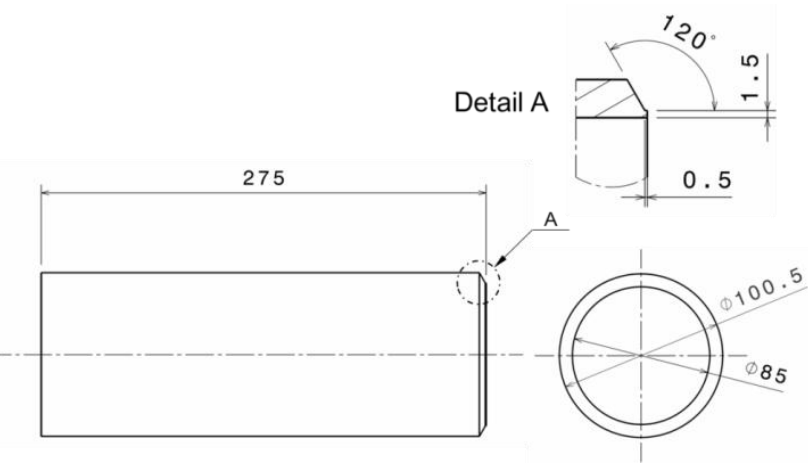

Fig. 2 Half of a sample used for studying residual stress relaxation with weld preparation

Two sample halves as depicted in Figure 2 were aligned coaxially with no gap, manually tack-welded at four points, each $90^{\circ}$ apart, and welded in the same way as the short samples. All specimens were metal active gas (MAG) welded with the filler wire ISO 14341-A-G 4Si1 of $1.0 \mathrm{~mm}$ diameter using a shielding gas of $82 \% \mathrm{Ar}$ and $18 \% \mathrm{CO}_{2}$. Mechanized welding was performed in flat position with a fixed welding torch and the sample being mounted on a motor-driven rotary table. Two passes were applied at room temperature, the second one with a pulsed current, resulting in nominal energy inputs 
of about $9 \mathrm{~kJ} / \mathrm{cm}$ for the root pass and $12 \mathrm{~kJ} / \mathrm{cm}$ for the second pass. The welding parameters can be taken from Table 1. Both passes were welded in the same direction, the second pass being slightly offset circumferentially.

After welding, cross-sections of the weld and its vicinity were metallographically prepared in order to determine the microstructure and the hardness in the weld seam, the heat-affected zone and the base material. The two-dimensional hardness distribution was determined by the Ultrasonic Contact Impedance $(\mathrm{UCl})$ method with a measuring point distance of $0.2 \mathrm{~mm}$ in both axial and radial direction of the pipe.

Table 1 Welding parameters for girth welds

\begin{tabular}{cccccccccc}
$\begin{array}{c}\text { Pass } \\
\text { No. }\end{array}$ & $\begin{array}{c}\text { Welding } \\
\text { speed } \\
\text { [cm/min] }\end{array}$ & $\begin{array}{c}\text { Wire } \\
\text { feed } \\
{[\mathbf{m} / \mathbf{m i n}]}\end{array}$ & $\begin{array}{c}\text { Ground } \\
\text { time } \\
{[\mathrm{ms}]}\end{array}$ & $\begin{array}{c}\text { Pulse } \\
\text { time } \\
\text { [ms] }\end{array}$ & $\begin{array}{c}\text { Ground } \\
\text { current } \\
\text { [A] }\end{array}$ & $\begin{array}{c}\text { Welding } \\
\text { current } \\
\text { [A] }\end{array}$ & $\begin{array}{c}\text { Pulse } \\
\text { voltage } \\
{[\mathrm{V}]}\end{array}$ & $\begin{array}{c}\text { Welding } \\
\text { voltage } \\
\text { [V] }\end{array}$ & $\begin{array}{c}\text { Heat } \\
\text { input } \\
\text { [kJ/cm] }\end{array}$ \\
\hline 1 & 60 & 12.4 & - & - & - & 287 & - & 30.1 & 8.6 \\
\hline 2 & 35 & 8.9 & 3.4 & 2 & 53 & 223 & 39 & 28.0 & 11.8
\end{tabular}

\section{Residual Stress Analysis}

The residual stresses in the welded samples were determined both in the non-loaded state and after releasing the load using X-ray diffraction (XRD) and neutron diffraction (ND). The measurements were taken at points along lines perpendicular to the welding direction at $\varphi=90^{\circ}$, where $\varphi$ is the circumferential angle marking the welding direction and the start/stop location at $\varphi=0^{\circ}$. Due to the symmetry, measurements were only performed on one side of the weld centerline up to a distance of $60 \mathrm{~mm}$. The axial distance between two measurement points was chosen to be between 0.5 and 1 $\mathrm{mm}$ in close proximity to the weld, and between 2.5 and $5 \mathrm{~mm}$ far away from the weld. The coordinate $x$ specifies the axial distance of a certain point from the weld centerline, see also Figure 5 a.

An $\Omega$-diffractometer was used to determine the residual stresses in hoop and axial direction on the outer and inner surfaces of the pipes by XRD. The inner surfaces were only accessible after sectioning the tubes into four quarters, the released stresses being monitored by strain gauge measurements. Interference lines of $\mathrm{Cr}-\mathrm{K}_{\alpha}$ radiation originating from the $\{211\}$ lattice planes of ferrite, bainite or martensite were recorded in a $2 \theta$ interval of $151^{\circ}$ to $161^{\circ}$ using a point detector that was moved in steps of $0.1^{\circ}$ and held for $2 \mathrm{~s}$ at each position. This was done for eight tilt angles $\psi$ of $0^{\circ}, 13^{\circ}, 18^{\circ}, 27^{\circ}$, $33^{\circ}, 39^{\circ}, 42^{\circ}$ and $45^{\circ}$, allowing for an analysis of the shift of the interference line's center of gravity by the $\sin ^{2} \psi$ method. Previously, the $\mathrm{K}_{\mathrm{a} 2}$ doublet was eliminated using the Rachinger technique [20] and the remaining $\mathrm{K}_{\alpha 1}$ peak was smoothed with a Savitzky-Golay filter [21]. Exemplary raw peaks are shown in Figure 3 a for every region of the weld. For all measurements, a collimator of $2 \mathrm{~mm}$ in diameter was used. The average penetration depth in steel is about $5 \mu \mathrm{m}$ for $\mathrm{Cr}-\mathrm{K}_{\alpha}$ radiation.

a)

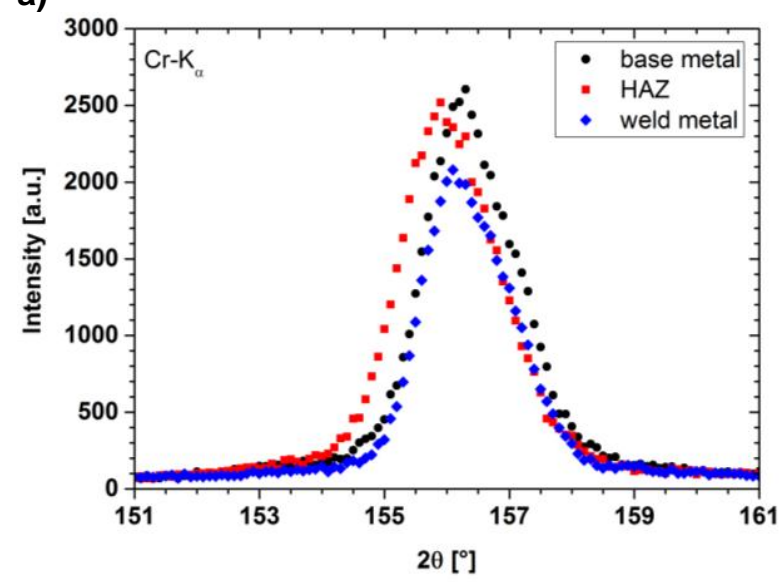

b)

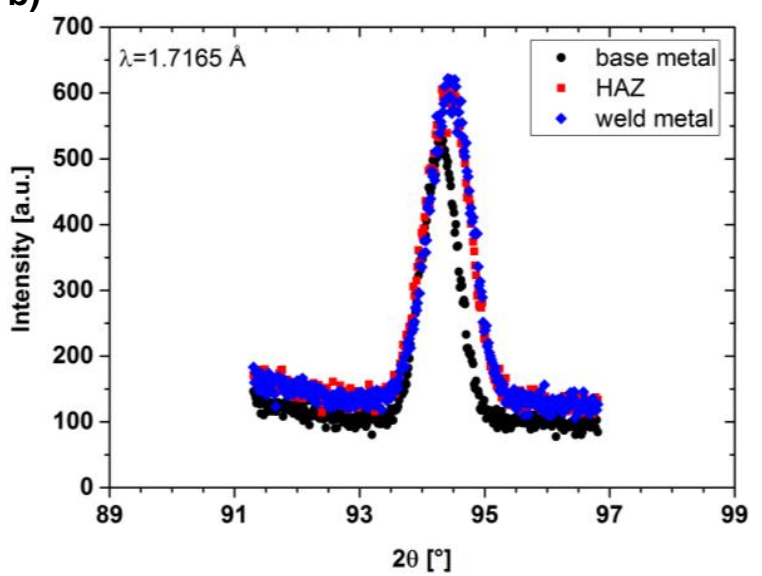

Fig. 3 Exemplary diffraction peaks from the different microstructural zones: a) XRD, b) ND

The neutron diffraction measurements for the residual stress analysis within the pipe wall were carried out using the $2^{\text {nd }}$ Generation Neutron Residual Stress Mapping Facility (NRSF2) beam line [22] at the High Flux Isotope Reactor (HFIR), Oak Ridge National Laboratory. The diffraction of neutrons with a wavelength of $\lambda \approx 1.72 \AA$ on the $\{211\}$ lattice planes was analyzed, in order to attain a diffraction angle 
$2 \theta$ close to $90^{\circ}$. This plane was chosen due to its similarity to the expected bulk stress/strain response of ferritic steel. Additionally, this reflection is reported to be the least-sensitive to intergranular strains [23]. The peaks were recorded by seven line detectors that are vertically arranged. The data from each detector were corrected, e.g. for peak shifts due to the shape of the diffraction cone, combined to a single peak and fitted with a pseudo-Voigt function to determine the peak position. Exemplary raw peaks are shown in Figure $3 \mathrm{~b}$ for every region of the weld.

The stress-free lattice spacing $D_{0}$ was separately determined in the base metal $(B M)$, the weld metal (WM) and the heat-affected zone (HAZ) to take composition gradients into account. To this end, a sample comprising the different zones was cut out of a welded pipe, see Figure 4, and subjected to the same stress-relieving heat treatment as described in the previous section. Since the measurements were taken during different reactor cycles and slight variations of the neutron wavelength can occur from cycle to cycle, the following strategy was adopted to determine the stressfree lattice spacings. The relative differences between the different microstructural zones were determined for each cycle and averaged over the involved reactor cycles. Thereby, the same relative differences could be used for the evaluation of all the measurements, using $D_{0}$ in the base metal as a cycle-specific reference. The results of this analysis are summarized in Table 2 . Since the absolute stress-free lattice spacings are about $1.170 \AA$, the relative difference between base and weld metal is significant, but smaller than the change of the lattice parameter due to residual stress, which can be in the order of up to about $0.0014 \AA$.

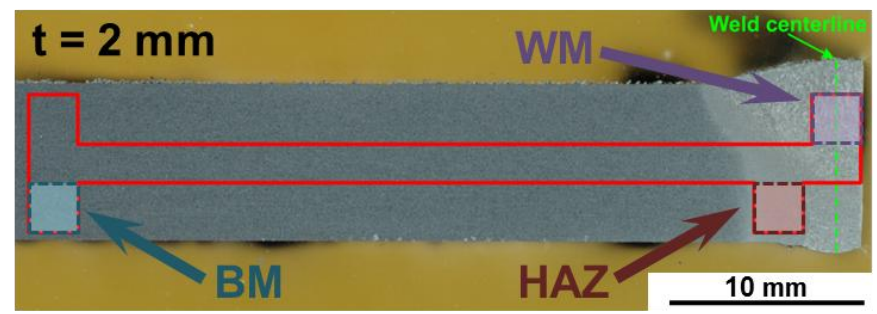

Fig. 4 Specimen geometry (thickness $2 \mathrm{~mm}$ ) for the determination of the stress-free lattice spacings

Table 2 Relative differences of the stress-free lattice spacing $D_{0}$ compared to the base metal in $\AA$

\begin{tabular}{lcc} 
& Heat-affected zone (HAZ) & Weld metal (WM) \\
\hline Cycle 1 & -0.000171 & -0.000250 \\
Cycle 2 & -0.000133 & -0.000407 \\
Cycle 3 & 0.000230 & -0.000027 \\
\hline Average & -0.000024 & -0.000228
\end{tabular}

For strain mapping, measurements were taken at five points that were evenly distributed across the wall thickness at each axial position. At every point, the strain was determined in hoop, axial and radial direction, assuming that these are the principal directions, in order to compute the multiaxial residual stress state. The measurement volume was cubical with an edge length of $2 \mathrm{~mm}$. A measurement uncertainty of $100 \mu \mathrm{m} / \mathrm{m}$ was assumed for the strains computed from the lattice spacings, resulting in residual stress uncertainties of about $30 \mathrm{MPa}$. The assumed uncertainty is based on an experimental analysis of the instrument's absolute resolution [24], which is more comprehensive than taking only the fitting error into account.

For both the XRD and the ND measurements, the residual stresses were computed from the strains determined in the ferrite phase by means of the elastic constants $E^{\{211\}, \alpha-F e}=210500 \mathrm{~N} / \mathrm{mm}^{2}$ and $v^{\{211\}, \alpha-F e}=0.28$. These values were experimentally determined by XRD for a specimen made of the same steel grade under uniaxial load. Due to its low mass percentage, the cementite phase was not analyzed in this study.

Four-point bending was applied to the samples of $550 \mathrm{~mm}$ length as shown in Figure $5 \mathrm{a}$ and $\mathrm{b}$ to generate an axial load stress. To this end, a servohydraulic testing machine with a nominal maximum load of $630 \mathrm{kN}$ was used, fabricated by the company walter+bai ag. The load was introduced by four sleeves that were put over the pipe and featured an interface with the testing machine. The axial contact length of the pipe and the sleeves was $9 \mathrm{~mm}$ in order to prevent local plasticity and buckling of 
the pipe, see Figure 5 a. The samples were mounted in a way that the maximum tensile load stress due to bending occurred at $\varphi=90^{\circ}$, whereas the location of the maximum compressive load stress was $\varphi=270^{\circ}$. The maximum nominal load stress was determined by a strain gauge that was applied at $x=50 \mathrm{~mm}$ and used for a generalized computation of the load stress distribution according to

$$
\sigma_{a}^{L S}(z)=E \cdot \varepsilon \cdot \frac{r_{i}+z}{r_{o}}
$$

where $E=206000 \mathrm{~N} / \mathrm{mm}^{2}$ is the bulk elastic modulus of a low-carbon steel, $\varepsilon$ is the strain measured by the strain gauge, $z$ is the distance from the inner surface, and $r_{i}$ and $r_{0}$ are the inner and outer radius of the pipe, respectively, see Figure 5 a. Equation 1 reflects the fact that the bending load induces axial stresses that vary linearly across the wall thickness.

a)

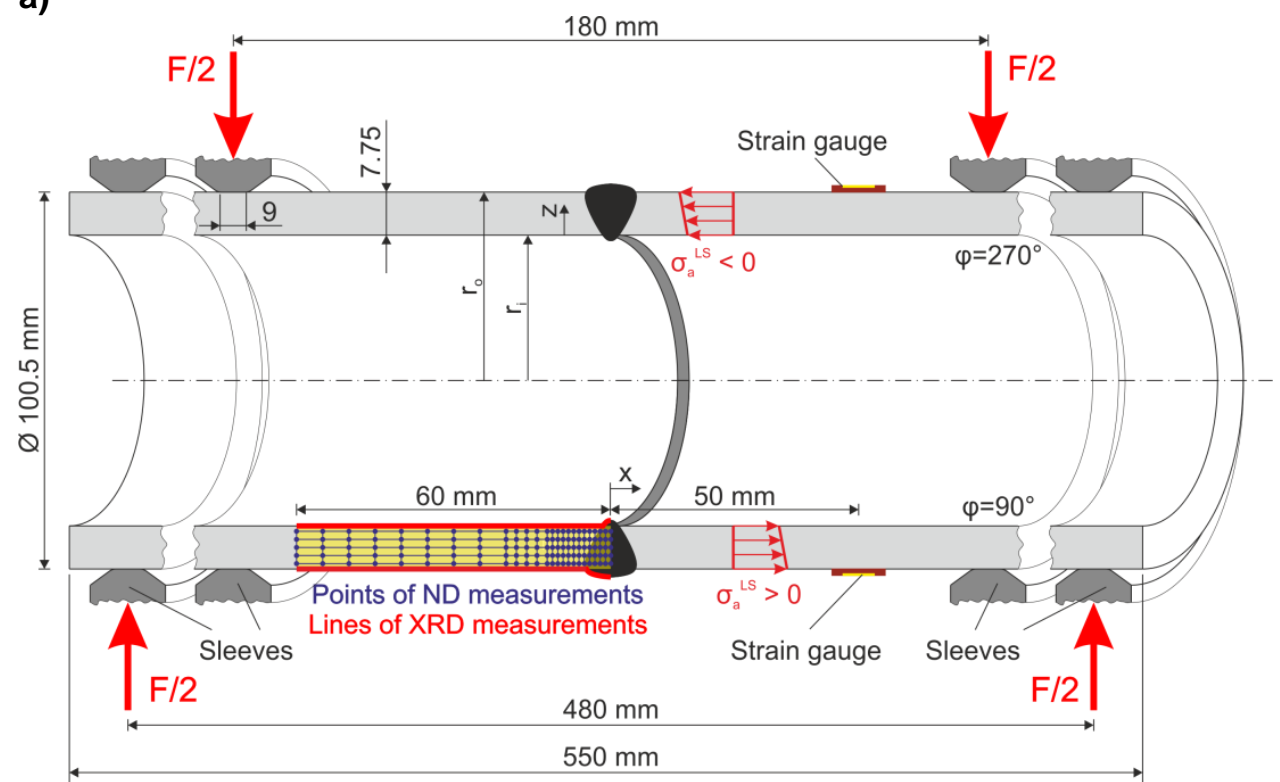

b)

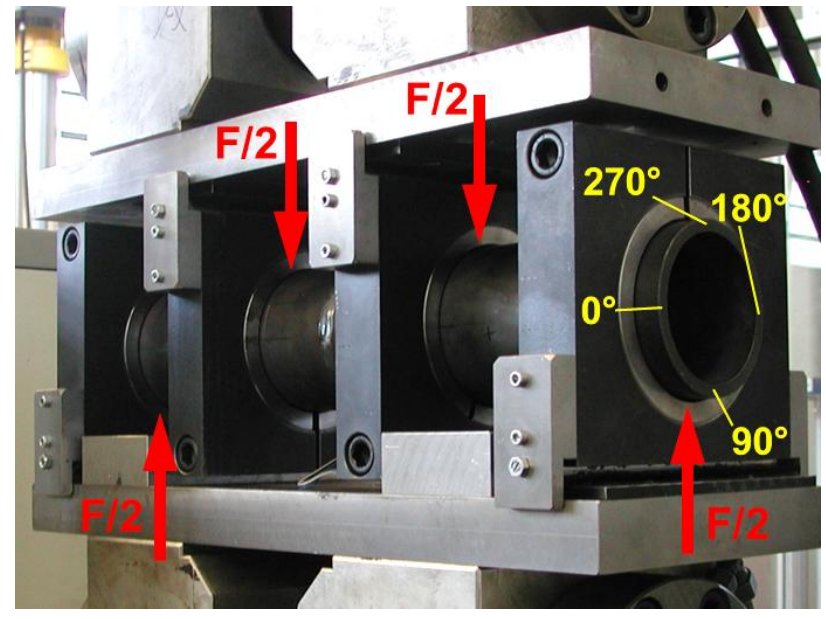

Fig. 5 Tubular sample under four-point bending: a) schematic drawing (not to scale) with locations of diffraction measurements, b) picture of the setup, showing the circumferential position of the pipe

For the quasi-static one-time loading the force was increased slowly by $2 \mathrm{kN} / \mathrm{s}$ up to maximum loads of $\mathrm{F}=132 \mathrm{kN}$ or $\mathrm{F}=248 \mathrm{kN}$, where it was held for at least 30 seconds before being released with the same slope. The load levels were chosen to attain maximum nominal load stresses of $50 \%$ and $95 \%$ of the yield strength, respectively. The residual stresses were analyzed after unloading. 


\section{Experimental results}

\section{Optical microscopy and hardness distribution}

Figure 6 shows a macrograph of the weld cross-section as well as the hardness distribution in the weld and its vicinity. It can be observed that the highest hardness values occur in the coarse-grained zone close to the fusion line. Here, the hardness reaches values of up to $285 \mathrm{HV} 1$, whereas in the base metal about $140 \mathrm{HV} 1$ are found.

a)

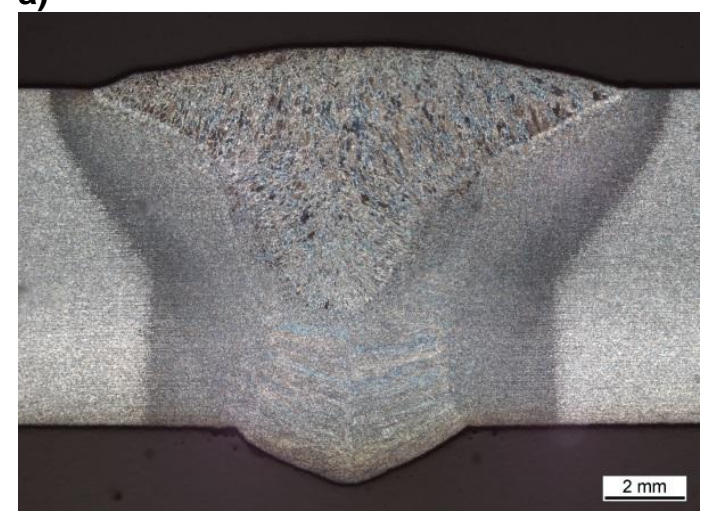

b)

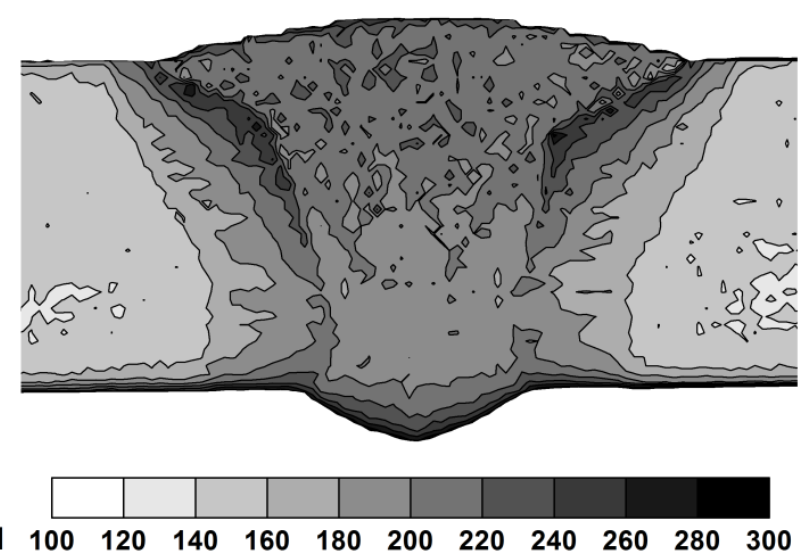

Fig. 6 Cross-section of the weld and its vicinity at $\varphi=135^{\circ}$ : a) macrograph, b) hardness distribution

In Figure 7, micrographs of the different microstructures are depicted. The base material consists of ferrite and pearlite, which has formed in bands, see Figure 7 a. In the HAZ and the weld metal, especially in the coarse-grained zone depicted in Figure $7 \mathrm{c}$, a predominantly bainitic structure can be observed. Computations using the predictive software WeldWare [25], where the temperature-time curve measured in the HAZ at the surface and the chemical composition of the base material were input, revealed a martensite content of about $5 \%$. The hardness in the coarse-grained zone as shown in Figure $6 \mathrm{~b}$ also indicates a small amount of martensite. 
a)

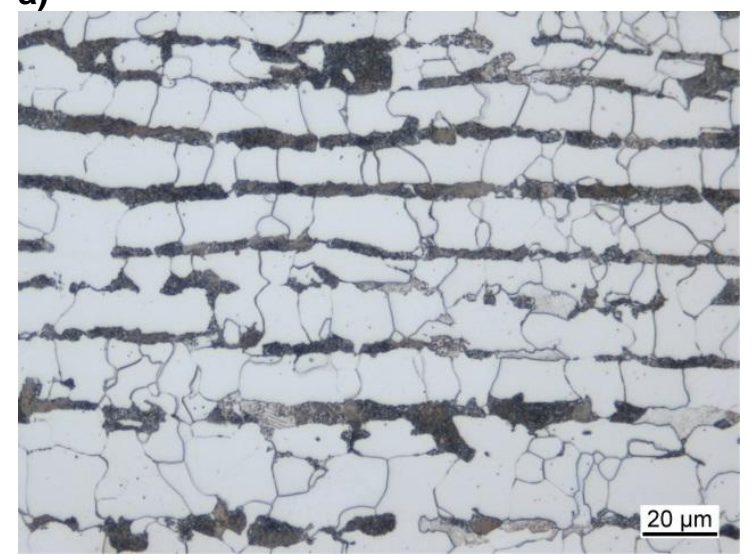

c)

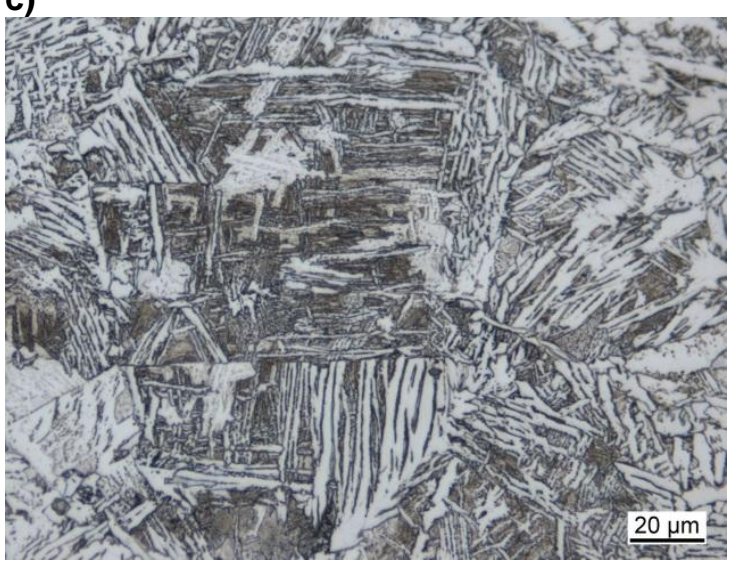

b)

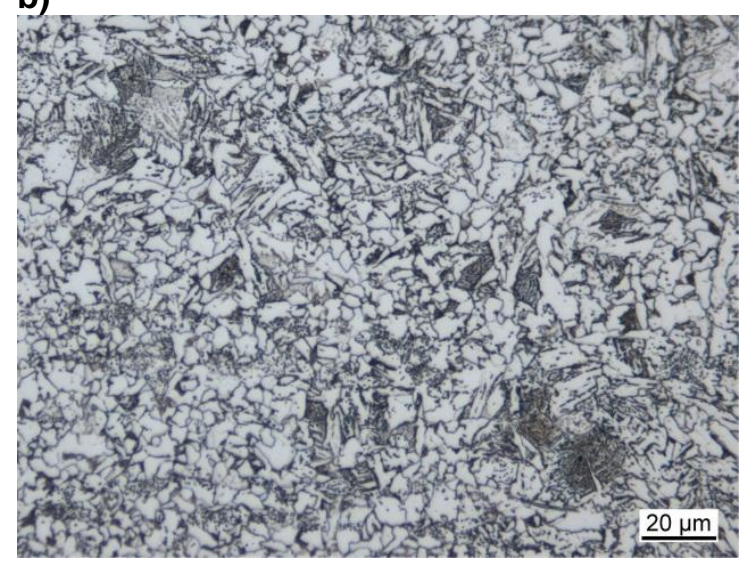

d)

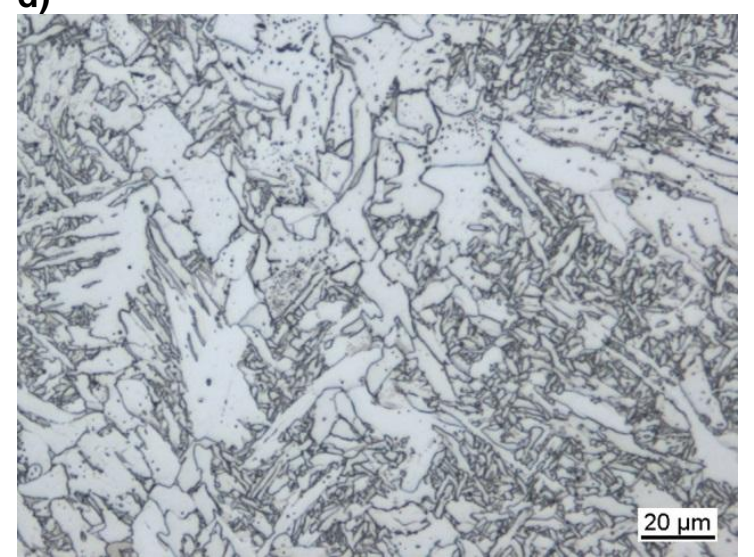

Fig. 7 Micrographs: a) base material, b) HAZ (fine grain), c) HAZ (coarse grain), d) weld metal

\section{Residual stress relaxation parallel to the applied load stress}

The behavior of the axial residual stresses, which are oriented parallel to the applied load stress, under quasi-static loading will be analyzed in the following. Figures 8 a and $b$ depict the residual stresses on the outer surface before and after axial load stresses of 182 and $337 \mathrm{MPa}$ were applied, respectively. The measurements were each taken on the same samples using XRD. A load stress of about $50 \%$ of the yield stress does not result in any change of the residual stresses, as shown in Figure 8 a. The very small variations that can be observed are within the measurement uncertainty, represented by error bars. A load stress equivalent to about $95 \%$ of the yield stress, however, does affect the residual stress state on the outer surface, see Figure $8 \mathrm{~b}$. For $|x|<18 \mathrm{~mm}$, i.e. in the weld seam, the heat-affected zone and the base material close to the weld, the compressive residual stresses are reduced. For instance, the values are about $80 \mathrm{MPa}$ lower at the compressive maximum at $x=-9 \mathrm{~mm}$, and differ by $100 \mathrm{MPa}$ at the weld centerline. At $40 \mathrm{~mm}<|x|<50 \mathrm{~mm}$, a relaxation of the tensile residual stresses can be observed, resulting in almost zero residual stress.

The axial residual stresses on the inner surface for the as-welded state, as well as after a load stress of $285 \mathrm{MPa}$ was applied, are depicted in Figure 9 . Since the inner surface was only accessible after sectioning and thus destroying a sample, the residual stress states were determined in two different samples. It can be seen that the tensile residual stresses in the vicinity of the weld, which reach up to $300 \mathrm{MPa}$ in the as-welded state, are significantly reduced by the load equivalent to $80 \%$ of the yield stress. In the weld seam and its immediate vicinity, the formerly tensile residual stress is completely removed and even takes slightly compressive values. It should be noted that the weld geometry of the two samples varies slightly, as reflected by the dashed lines indicating the respective width of the weld root. The largest relaxation occurs at the residual stress maximum, which is $250 \mathrm{MPa}$ lower than in the initial state. Far away from the weld, i.e. for $|x|>30 \mathrm{~mm}$, there are only small differences between residual stresses determined in the two states. The residual stress states in both samples were affected by the sectioning process. Strain gauge measurements on the inner surface revealed a decrease of the tensile residual stresses of about $125 \mathrm{MPa}$ at $x=6 \mathrm{~mm}$ in the as-welded state and of about $50 \mathrm{MPa}$ at $x=7 \mathrm{~mm}$ after quasi-static loading. 
a)

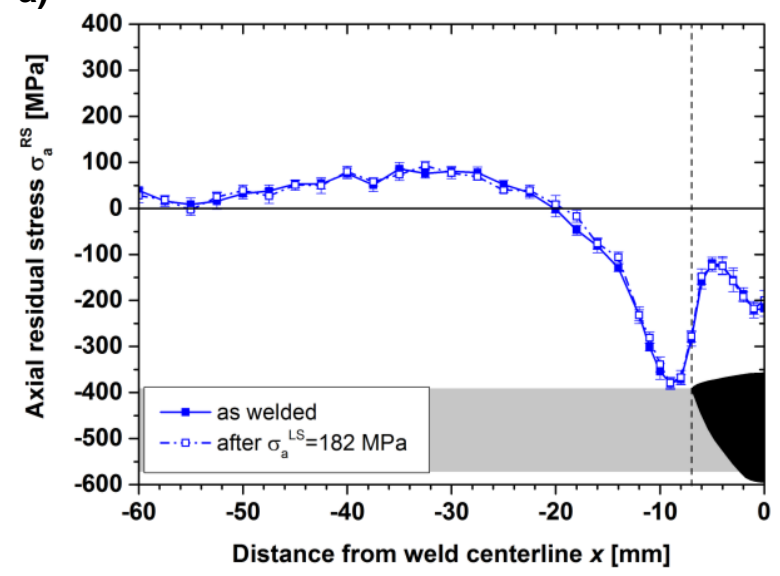

b)

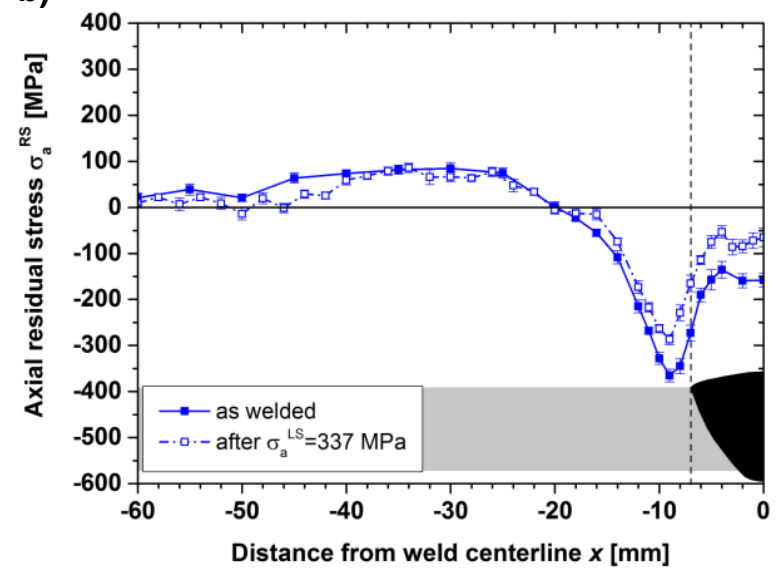

Fig. 8 Axial residual stresses on the outer surface: a) before and after an axial load of $182 \mathrm{MPa}$, b) before and after an axial load of $337 \mathrm{MPa}$

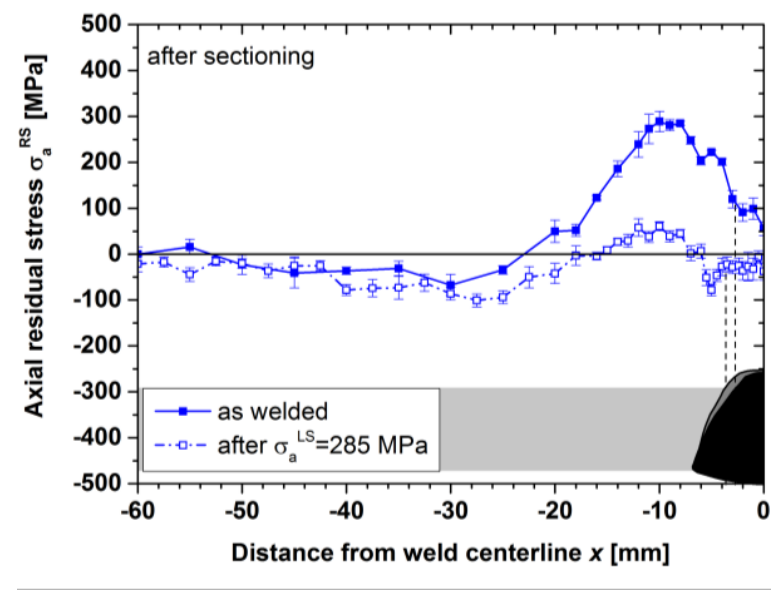

\section{Fig. 9 Axial residual stresses on the inner surface before and after an axial load of $285 \mathrm{MPa}$, after sectioning}

Changes of the residual stress state inside the pipe wall were determined using neutron diffraction. To this end, different samples were used to study the initial axial residual stresses, see Figure 10 a, as well as after maximum load stresses of $182 \mathrm{MPa}$ and $337 \mathrm{MPa}$, see Figures $10 \mathrm{~b}$ and c, respectively. Each diagram displays the cross section of the whole pipe wall; the white areas reflect the fact that the center of the fully immersed measurement volume had to be at least $1.5 \mathrm{~mm}$ away from the surfaces. The center positions of the measurement volume at each measuring point are also given. The dashed lines indicate the regions for which the three different stress-free lattice parameters were used. Due to the linear load stress distribution across the pipe wall, cf. Equation 1, the respective load stresses on the inner surface amount to $154 \mathrm{MPa}$ and $285 \mathrm{MPa}$. After a load of $182 \mathrm{MPa}$ on the outer surface, the residual stresses in the pipe wall, see Figure $10 \mathrm{~b}$, are almost identical to the as-welded state depicted in Figure $10 \mathrm{a}$, except for the area close to the weld root, where the tensile residual stresses are 60 to $110 \mathrm{MPa}$ lower. This effect becomes even more pronounced when a load stress of $337 \mathrm{MPa}$ (outer surface) is applied, leading to a residual stress relaxation that is most distinct at the measuring points closest to the inner surface, where it amounts to $170 \mathrm{MPa}$, see Figure $10 \mathrm{c}$. In contrast to the lower load, a relatively high load stress does not only result in a severe reduction of the tensile residual stresses near the weld root, but also in a relaxation of the compressive stresses originally occurring in and close to the weld zone near the outer surface. Furthermore, the tensile residual stresses near the outer surface and the compressive ones near the inner surface that are originally found at a larger distance from the weld centerline are still present, but are distributed more evenly along the $x$ coordinate, not exhibiting distinct maxima at about $x=-30 \mathrm{~mm}$ as seen in Figure 10 a. 
a)

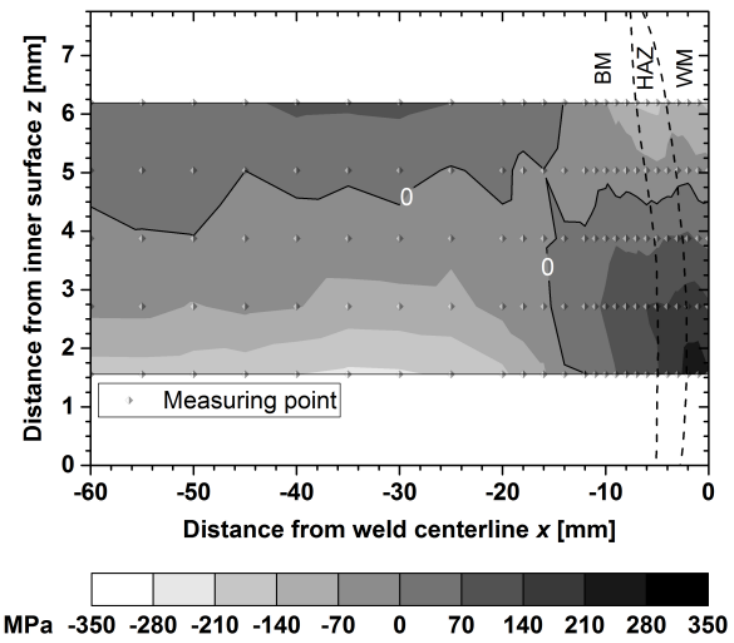

b)

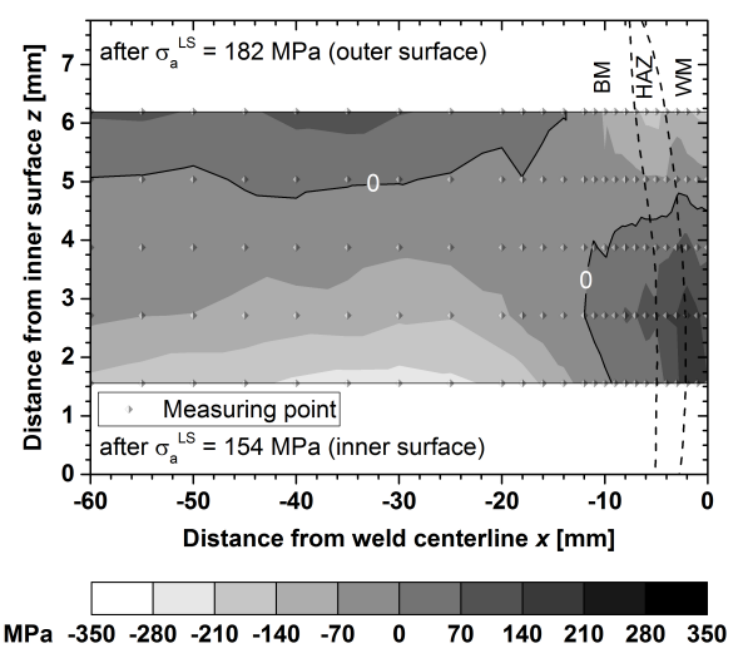

c)

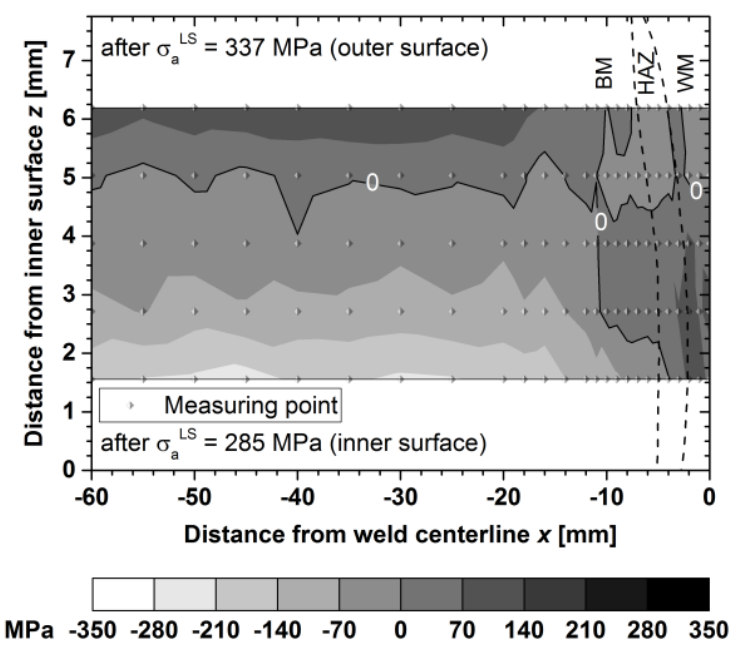

Fig. 10 Axial residual stresses in the pipe wall: a) as welded, b) after an axial load of $182 \mathrm{MPa}$ (outer surface), c) after an axial load of $337 \mathrm{MPa}$ (outer surface)

\section{Residual stress relaxation perpendicular to the applied load stress}

The hoop residual stresses on the outer surface are shown in Figures $11 \mathrm{a}$ and $\mathrm{b}$ before and after load stresses of 182 and $337 \mathrm{MPa}$ were applied, respectively. The measurements were each taken on the same samples. It can be seen that a load stress of about $50 \%$ of the yield strength does not result in significant stress relaxation, see Figure $11 \mathrm{a}$. The absolute values of the tensile residual stresses in the weld seam as well as at the compressive maximum near $x=-16 \mathrm{~mm}$ are reduced by about 30 $\mathrm{MPa}$; however, the measurement uncertainty is between 10 and $25 \mathrm{MPa}$ in these areas. A load stress of $337 \mathrm{MPa}$ leads to a more pronounced effect on the residual stresses, see Figure $11 \mathrm{~b}$. In the base material, a shift of the residual stress curve towards the tensile regime of about $60 \mathrm{MPa}$ can be observed for $14 \mathrm{~mm}<|x|<40 \mathrm{~mm}$. Thus, the compressive residual stresses in this area are either reduced or even become tensile. Close to the weld centerline, the tensile residual stresses in the weld seam are about $40 \mathrm{MPa}$ lower than in the initial state. 
a)

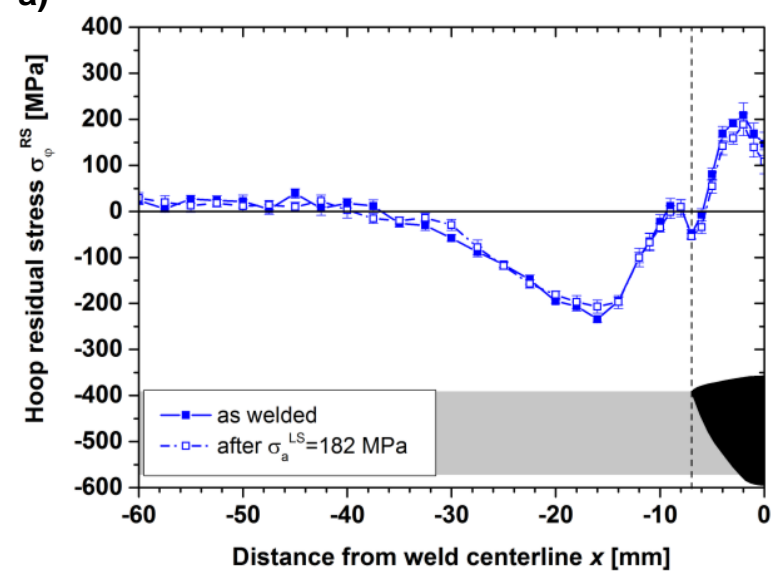

b)

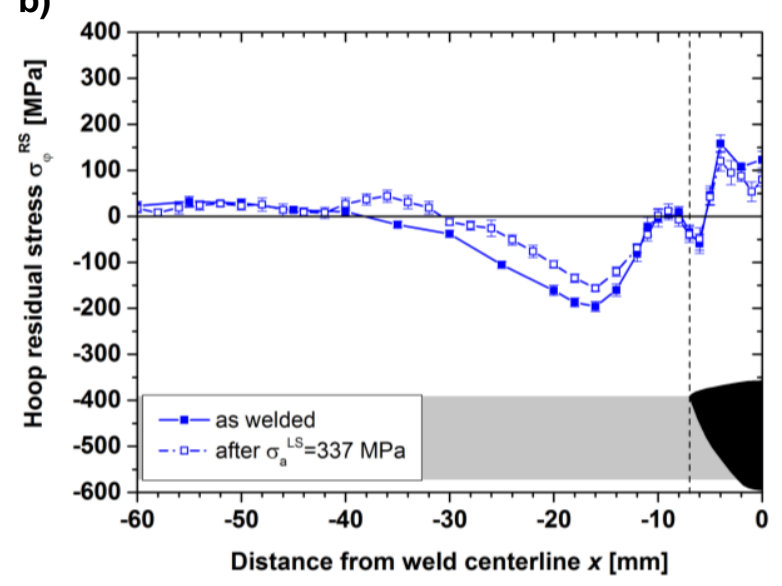

Fig. 11 Hoop residual stresses on the outer surface: a) before and after an axial load of 182 $\mathrm{MPa}, \mathrm{b})$ before and after an axial load of $337 \mathrm{MPa}$

The hoop residual stresses on the inner surface are depicted in Figure 12 for the as-welded state, as well as after a load stress of $285 \mathrm{MPa}$ was applied. The measurements were taken on different samples. The main effects of the load are found near the weld, where high tensile stresses occur in the as-welded state. Within the weld seam, a decrease of the tensile residual stress by about $100 \mathrm{MPa}$ was determined, whereas the residual stress maximum of almost $500 \mathrm{MPa}$ is reduced to about 200 $\mathrm{MPa}$. Moreover, the curve taken from the loaded sample exhibits a minimum at the weld root notch, where the residual stress is about $0 \mathrm{MPa}$, which cannot be observed in the as-welded state. For 12 $\mathrm{mm}<|x|<20 \mathrm{~mm}$, the residual stresses are slightly less compressive after loading; however, almost the same maximum compressive stress of about $-200 \mathrm{MPa}$ is reached. For $|x|>20 \mathrm{~mm}$, where the compressive residual stresses asymptotically approach $0 \mathrm{MPa}$ with increasing distance from the weld, the two curves coincide almost perfectly. The influence of the sectioning process was monitored by strain gauge measurements on the inner surface, which revealed a decrease of the tensile residual stresses of about $100 \mathrm{MPa}$ at $x=6 \mathrm{~mm}$ in the as-welded state and of about $35 \mathrm{MPa}$ at $x=7 \mathrm{~mm}$ after quasi-static loading.

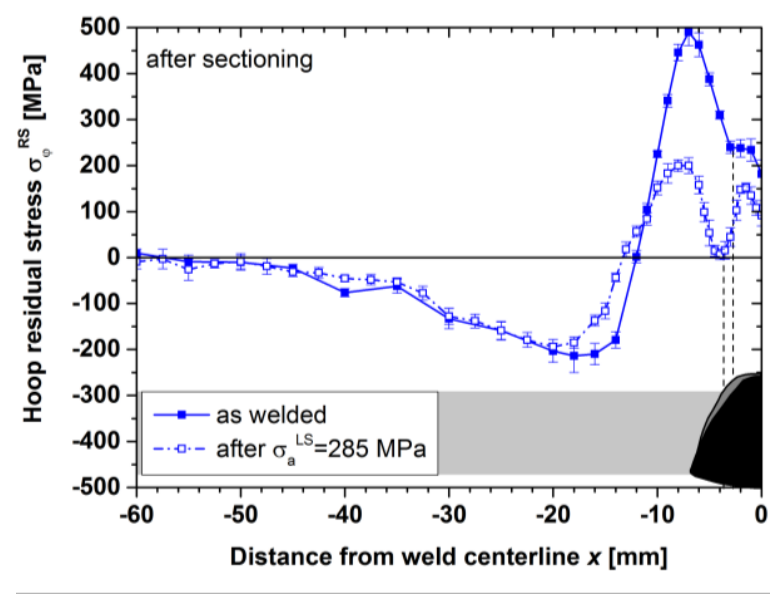

Fig. 12 Hoop residual stresses on the inner surface before and after an axial load of $285 \mathrm{MPa}$, after sectioning

The hoop residual stress distributions inside the pipe wall in the as-welded state and after axial load stresses of $182 \mathrm{MPa}$ and $337 \mathrm{MPa}$ (outer surface) have been applied are presented in Figures 13 a to $\mathrm{c}$, respectively. The original distribution in the as-welded state is characterized by tensile residual stresses in the vicinity of the weld, i.e. for $|x|<14 \mathrm{~mm}$, whereas at larger distances only compressive residual stresses are found, see Figure $13 \mathrm{a}$. The lower one of the two load levels only results in small changes of the residual stresses, as can be seen in Figure $13 \mathrm{~b}$. Most notably, the tensile residual stress in the weld region is reduced by up to $100 \mathrm{MPa}$ at the measuring points closest to the inner surface, whereas the tensile residual stresses near the outer surface are not affected at all. For $|x|>$ 
$14 \mathrm{~mm}$, a partial relaxation of the compressive residual stresses can be observed, being most distinct at the compressive maximum values, which is reduced by about $75 \mathrm{MPa}$ in the center of the pipe wall. Far away from the weld, a small area of tensile residual stresses develops near the outer surface.

The effects described for the low load level are also present in the sample subjected to the higher load, but to a larger extent, see Figure $13 \mathrm{c}$. Here, the tensile residual stress near the weld root is reduced by up to $130 \mathrm{MPa}$, whereas the compressive residual stresses are up to $170 \mathrm{MPa}$ lower. The compressive maximum near the inner surface is reduced by $110 \mathrm{MPa}$ and slightly shifted towards the weld. The area of tensile residual stress far away from the weld has both increased in size and features higher values than after applying the lower load.

a)

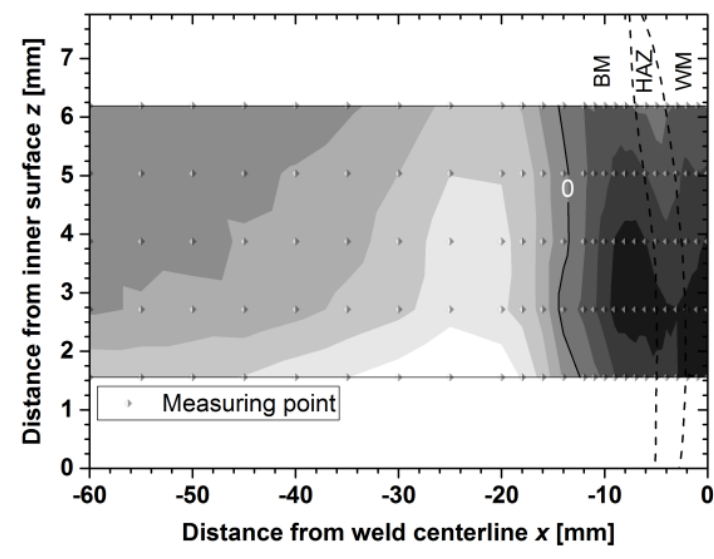

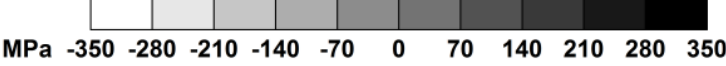

b)

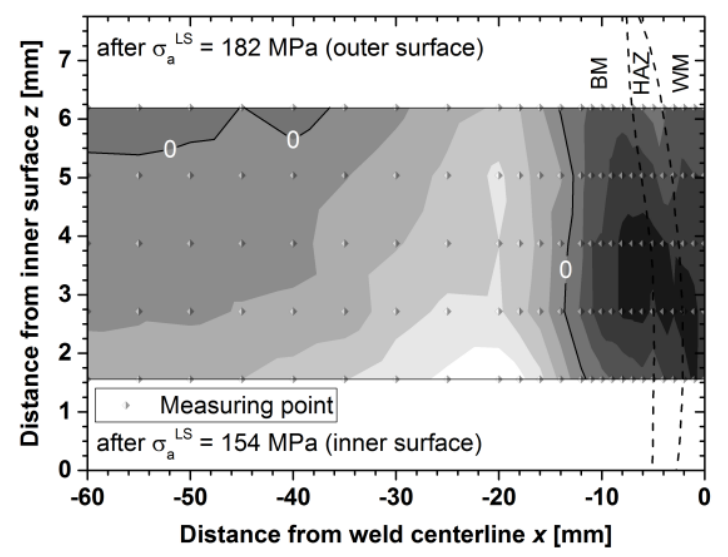

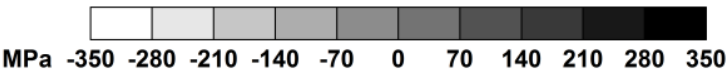

c)

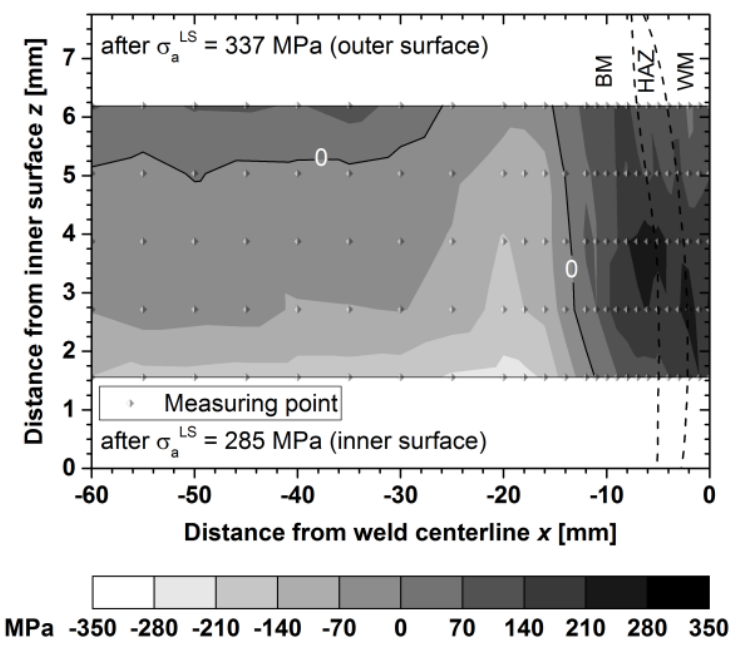

Fig. 13 Hoop residual stresses in the pipe wall: a) as welded, b) after an axial load of $182 \mathrm{MPa}$ (outer surface), c) after an axial load of $337 \mathrm{MPa}$ (outer surface)

Finally, the radial residual stress distributions inside the pipe wall are presented in Figures 14 a to $\mathrm{c}$. On the surfaces, this stress component is zero and will therefore only be discussed for the neutron diffraction measurements. In general, the absolute residual stress values are relatively low in the radial direction compared to the other components. In the as-welded state, a residual stress gradient can be observed across the pipe wall, featuring values in the range of the measurement uncertainty near the outer surface and compressive values of up to $-200 \mathrm{MPa}$ near the inner surface, see Figure $14 \mathrm{a}$. Within the weld metal, very small residual stresses are found across the whole wall thickness. Applying axial loads has no significant consequences on the radial residual stress state, as almost identical distributions are found after loading, see Figures $14 \mathrm{~b}$ and $\mathrm{c}$. 
a)

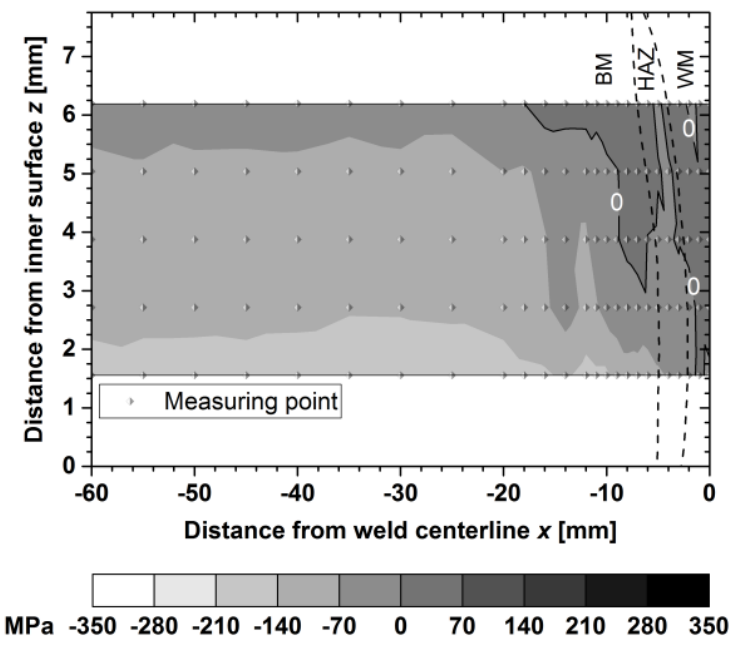

b)

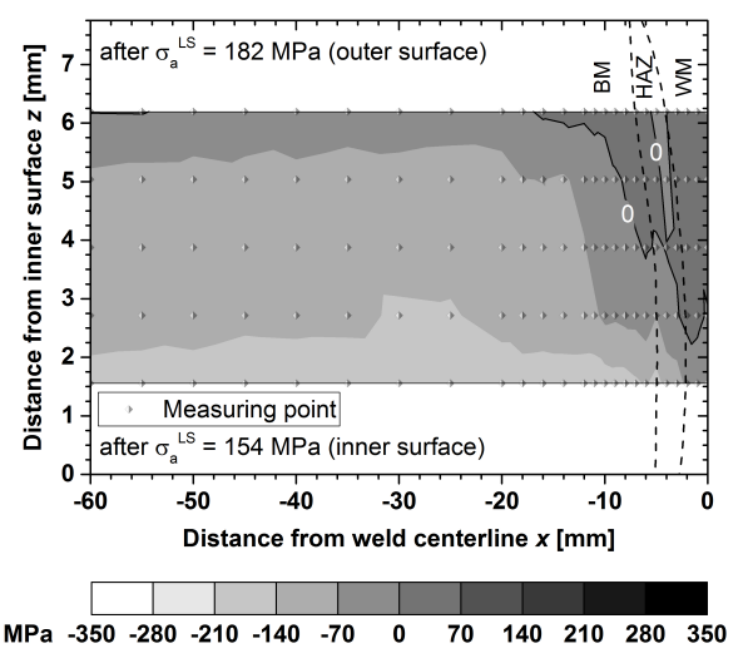

c)

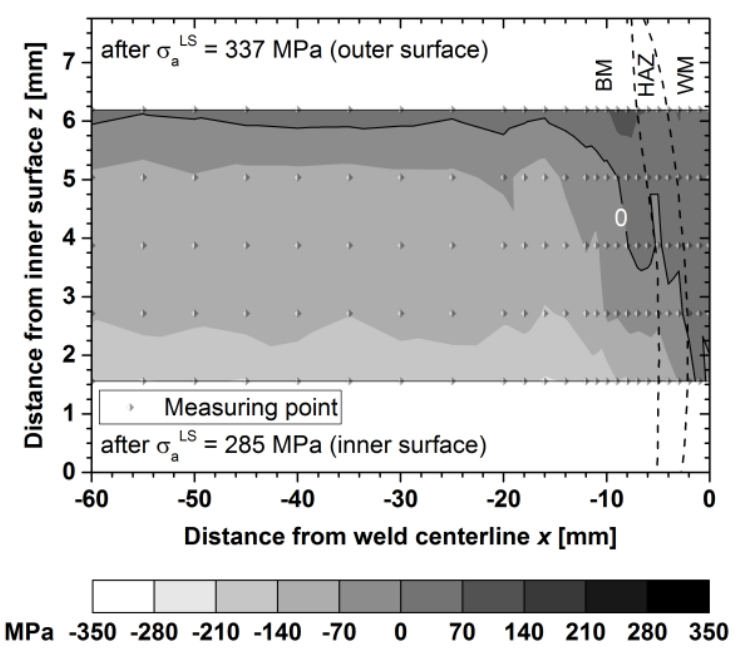

Fig. 14 Radial residual stresses in the pipe wall: a) as welded, b) after an axial load of $182 \mathrm{MPa}$ (outer surface), c) after an axial load of $337 \mathrm{MPa}$ (outer surface)

\section{Discussion}

It is well-known that residual stress relaxation due to mechanical loading occurs when the elastic strains accounting for the residual stresses are transformed into plastic strains [2]. To this end, the yield stress must be exceeded locally by the combined effect of residual and load stresses. Since the as-welded residual stress state in the tubular welds investigated in this study is highly multiaxial, an equivalent stress must be computed in order to discuss possible locations of plastic deformation and its effect on the residual stress state. For this purpose, the von Mises yield criterion is used, comparing the equivalent stress

$$
\sigma_{v M}=\sqrt{\frac{1}{2}\left[\left(\sigma_{r}^{R S}-\sigma_{\varphi}^{R S}\right)^{2}+\left(\sigma_{\varphi}^{R S}-\left(\sigma_{a}^{R S}+\sigma_{a}^{L S}\right)\right)^{2}+\left(\left(\sigma_{a}^{R S}+\sigma_{a}^{L S}\right)-\sigma_{r}^{R S}\right)^{2}\right]}
$$

to the yield stress $\sigma_{y}$, see also [2]. In Equation 2, $\sigma_{r}^{R S}, \sigma_{\varphi}^{R S}$ and $\sigma_{a}^{R S}$ are the residual stress components in radial, hoop and axial direction, respectively, whereas $\sigma_{a}^{L S}$ is the axial load stress computed according to Equation 1. In order to discuss the results presented in the first part of this paper, the equivalent stress is determined at every point of measurement, applying two simplifications. First, the yield stress $\sigma_{y}$ is assumed to be $355 \mathrm{MPa}$ in the base material, i.e. its upper yield point, and $460 \mathrm{MPa}$ in the weld metal, not taking local changes of the yield stress due to structural hardening in the heataffected zone into account. Second, the nominal load stress determined through strain gauge 
measurements, see Equation 1, is used independently of the distance from the weld centerline $x$, i.e. stress concentration effects at the weld toe and weld root, as well as the fact that the cross-sectional area is larger in the weld seam, are not considered.

In general, it should be noted that the residual stress analysis by XRD is susceptible to uneven surfaces as they occur in welded joints. Therefore, the XRD results from those areas where the incline with respect to the pipe surface is high should be used with care. This is specifically true for the weld root, as can be seen in Figure 6 a.

a)

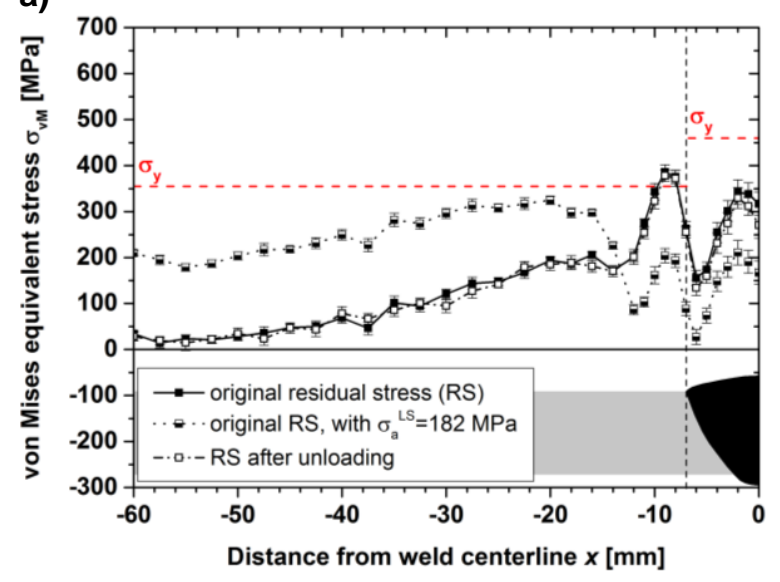

b)

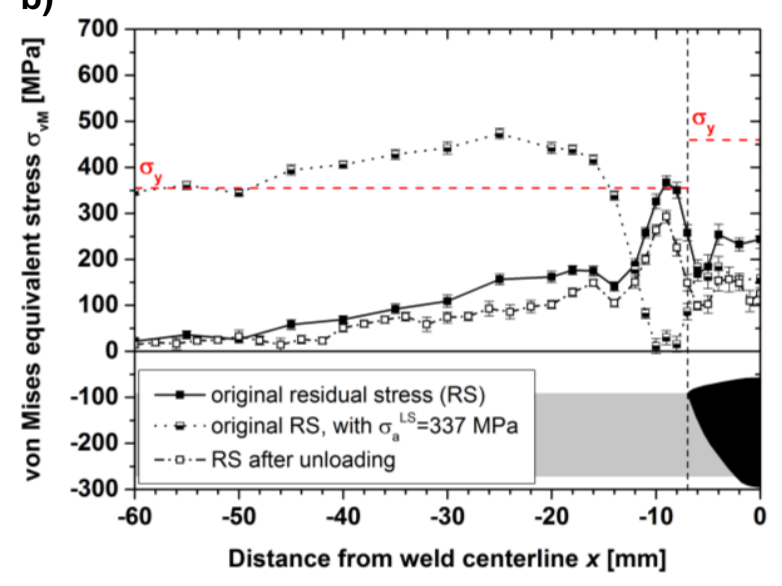

Fig. 15 Von Mises equivalent stress on the outer surface: a) before, during and after an axial load of $182 \mathrm{MPa}, \mathrm{b}$ ) before, during and after an axial load of $337 \mathrm{MPa}$

In Figure 15, the equivalent stress curves on the outer surface are shown for the initial residual stresses in the as-welded state, the stress state during loading, and the residual stresses after unloading. For the lower load of $182 \mathrm{MPa}$, it can be seen that the von Mises stress during loading does not reach the yield stress at any point, see Figure $15 \mathrm{a}$, thus explaining why no relaxation effect can be observed in the residual stresses as shown in Figures $8 \mathrm{a}$ and $11 \mathrm{a}$. The fact that the residual stresses surpass $\sigma_{y}$ at $x=-9 \mathrm{~mm}$ even though no load is applied can be ascribed to structural hardening in the heat-affected zone, leading to a locally increased yield strength.

A load stress of $337 \mathrm{MPa}$, however, results in an exceeding of the yield stress for $14 \mathrm{~mm}<|x|<50$ $\mathrm{mm}$. In this area, the equivalent residual stress after unloading is smaller than in the as-welded state, indicating a relaxation effect. Interestingly, the residual stress components are affected to different extents. For $14 \mathrm{~mm}<|x|<40 \mathrm{~mm}$, changes can only be observed for the hoop residual stress, see Figure $11 \mathrm{~b}$, whereas for $40 \mathrm{~mm}<|x|<50 \mathrm{~mm}$ only the axial component is affected, as shown in Figure $8 \mathrm{~b}$. For $|x|<14 \mathrm{~mm}$, i.e. in and close to the weld seam, the equivalent stress of residual and load stresses takes rather low values, since the tensile load stress is compensated by the compressive axial residual stress. Nevertheless, the absolute residual stress values in the weld area are reduced after unloading, especially in the axial direction, see Figure $8 \mathrm{~b}$. As the yield strength is not exceeded here, this effect can be attributed to a residual stress redistribution due to relaxation occurring at or near the inner surface, which will be analyzed in the following.

For the inner surface, the results of the equivalent stress analysis are presented in Figure 16. It can be seen that the yield stress is considerably exceeded at $3 \mathrm{~mm}<|x|<25 \mathrm{~mm}$, i.e. in the base material and the heat-affected zone, when an axial load stress is applied. Accordingly, the equivalent residual stresses before and after loading differ significantly in this area, documenting the strong relaxation effect observed both in axial and hoop direction, see Figures 9 and 12. However, although the equivalent stress under load does not surpass $\sigma_{y}$ at the weld root notch, both the axial and the hoop residual stresses are reduced to about $0 \mathrm{MPa}$. One reason for that behavior is the stress concentration due to the notch effect, resulting in higher actual load stresses than those assumed in the equivalent stress analysis. A similar observation can be made to a lesser extent within the weld seam, where residual stress relaxation occurs despite the fact that the von Mises stress does exceed the yield strength of the weld metal. However, this phenomenon cannot be explained by a notch effect. Rather, it was found through strain gauge measurements that the sectioning of the pipes influences the residual stress state on the inner surface, see also $[18,26]$. In fact, the original residual stresses at the weld root were higher, thus resulting in equivalent stresses that have surpassed the yield strength in combination with the load stress. This conclusion is also confirmed by the neutron diffraction measurements that will be discussed in the following. 


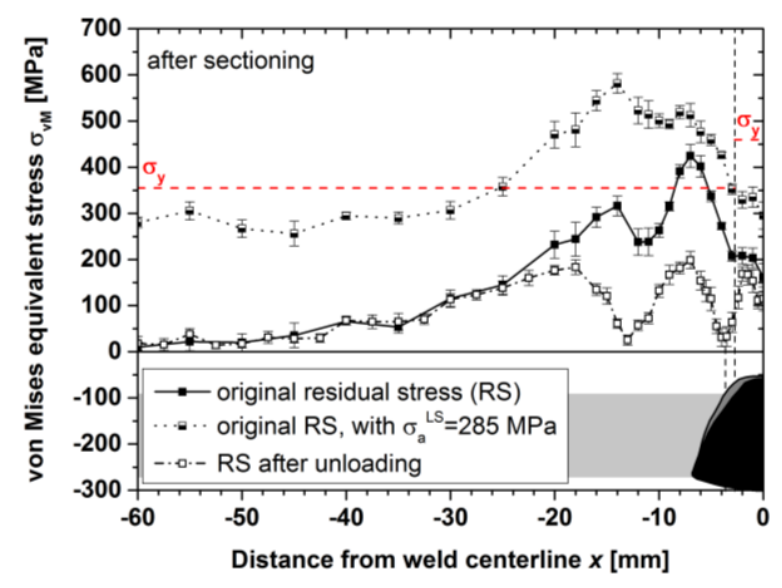

\section{Fig. 16 Von Mises equivalent stress on the inner surface before, during and after an axial load of $285 \mathrm{MPa}$}

Contour plots showing the equivalent stress inside the pipe wall in the as-welded state, as well as during and after the two different loads are applied, are presented in Figure 17. It can be taken from Figure 17 a that initially, the highest equivalent residual stresses occur in the highly-heated area in and close to the weld and at $18 \mathrm{~mm}<|x|<30 \mathrm{~mm}$. When loading is applied, these areas are most susceptible to plastic yield. It can be seen in Figure $17 \mathrm{~b}$ that, according to the equivalent stress analysis, the yield stress of the base material is exceeded due to a load stress of $182 \mathrm{MPa}$ (outer surface) near the outer surface at $x=-25 \mathrm{~mm}$ and near the weld root notch. However, the equivalent stress near the outer surface in the weld zone and the HAZ has decreased, which is due to the different signs of the local axial residual and load stresses. Accordingly, residual stress relaxation close to the weld can only be observed near the inner surface both in axial and hoop direction, see Figures $10 \mathrm{~b}$ and $13 \mathrm{~b}$, respectively, which is also reflected by the equivalent residual stress distribution shown in Figure $17 \mathrm{c}$. In the region of $18 \mathrm{~mm}<|x|<30 \mathrm{~mm}$, the hoop residual stresses are reduced across the whole wall thickness, see Figure $13 \mathrm{~b}$, although the equivalent stress analysis suggests only near-surface yielding. However, the von Mises stress values in this zone are close to the yield stress for a relatively large area, so that they might actually surpass the yield strength, taking the uncertainty of the von Mises stress of about $40 \mathrm{MPa}$ into account.

When a load stress corresponding to $95 \%$ of the yield strength on the outer surface is applied, the equivalent stress analysis shows an extensive exceeding of the base material's yield strength in almost the whole area under consideration, see Figure $17 \mathrm{~d}$. The highest values are again reached at the locations already highlighted for the lower load stress, whereas the lowest values can be found close to the weld near the outer surface. While the first finding explains the relaxation of the compressive hoop residual stress at $18 \mathrm{~mm}<|x|<30 \mathrm{~mm}$, see Figure $13 \mathrm{c}$, and of both axial and hoop residual stresses near the weld root, as shown in Figures $10 \mathrm{c}, 13 \mathrm{c}$ and $17 \mathrm{e}$, the latter finding seemingly contradicts the significant reduction of the compressive axial residual stresses in the weld and its vicinity near and at the outer surface, see Figures $10 \mathrm{c}$ and $8 \mathrm{~b}$, respectively. However, it can be inferred that the pronounced reduction of the axial residual stress at the weld root results in a redistribution of the axial residual stress across the whole pipe wall in the weld, since the equilibrium of forces and moments in axial direction must still be satisfied after relaxation has taken place. It should be noted that after applying a bending load the residual stress state is not axisymmetric anymore, as it is after welding, see $[17,18]$.

A similar case can be made for the hoop component, where compressive residual stresses are significantly reduced in the area of $18 \mathrm{~mm}<|x|<30 \mathrm{~mm}$. Since this effect is more pronounced than the simultaneous relaxation of tensile hoop residual stresses near the weld root, and equilibrium must also be satisfied in the hoop direction, stress redistribution leads to the formation of a small area of tensile residual stresses near the outer surface, which can be seen in Figures $13 \mathrm{c}$ and $11 \mathrm{~b}$. 
a)

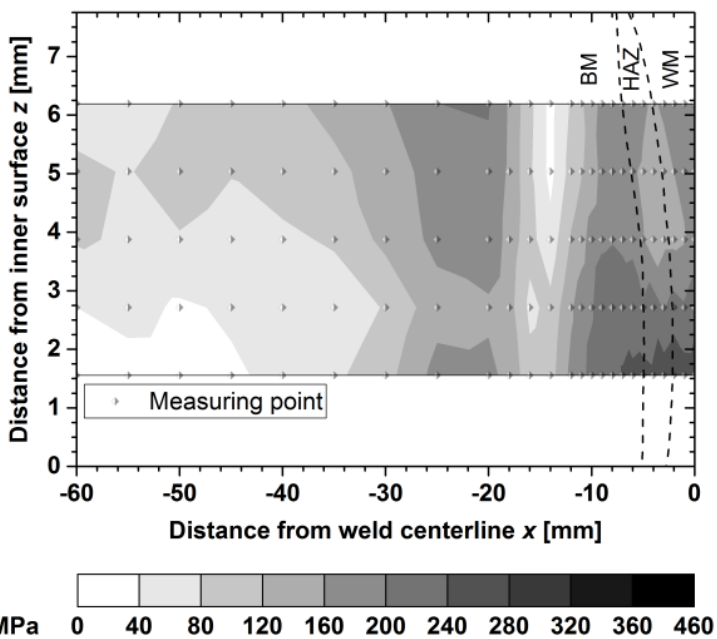

b)
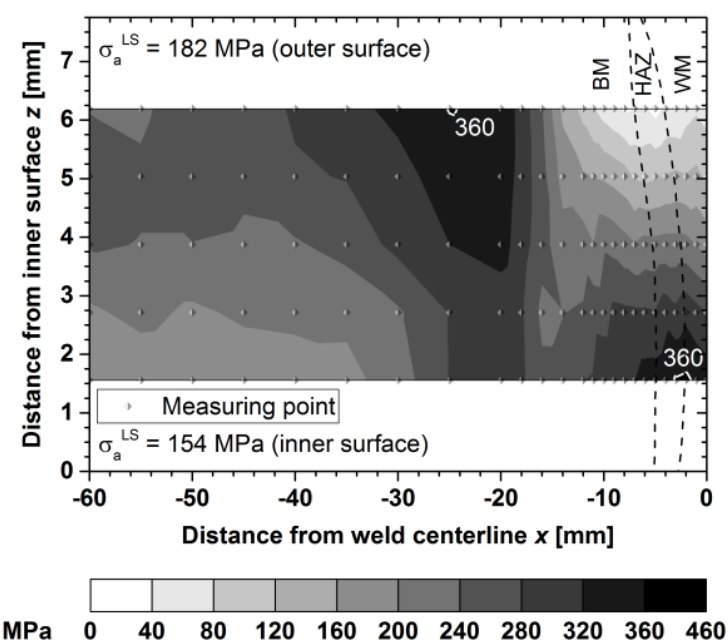

d)

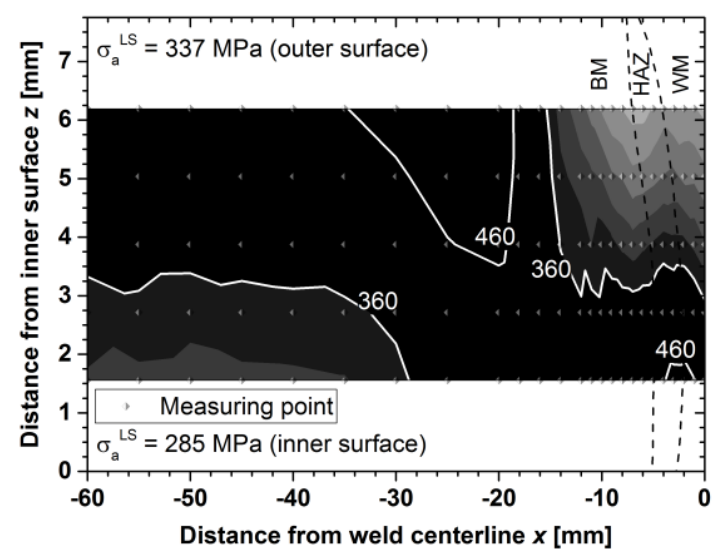

$\begin{array}{llllllllllll}\text { MPa } & 0 & 40 & 80 & 120 & 160 & 200 & 240 & 280 & 320 & 360 & 460\end{array}$ c)
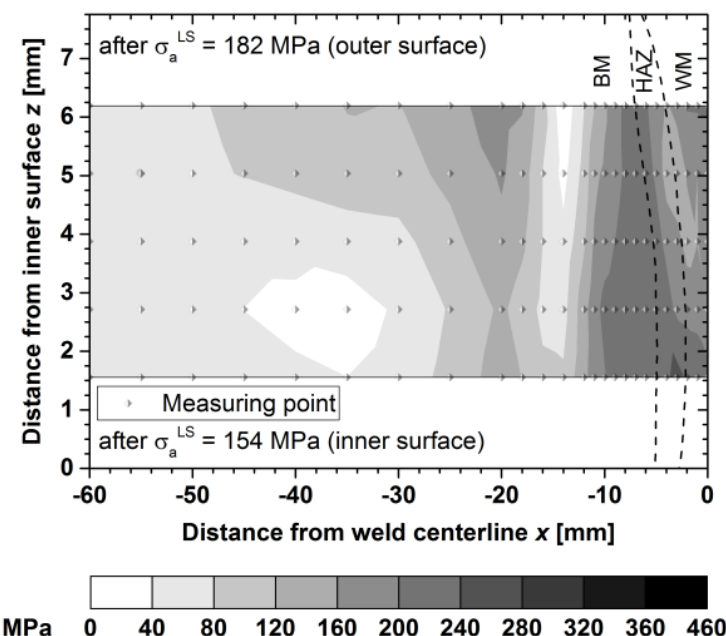

e)

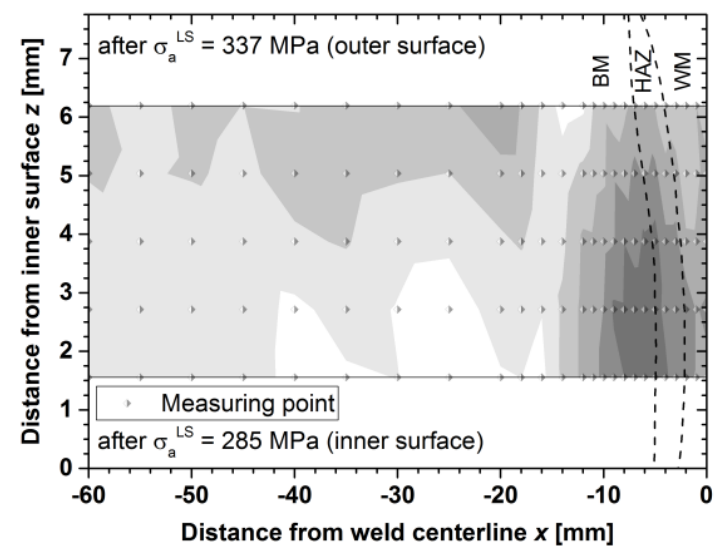

$\begin{array}{llrrrrrrrrrr}\text { MPa } & 0 & 40 & 80 & 120 & 160 & 200 & 240 & 280 & 320 & 360 & 460\end{array}$

Fig. 17 Von Mises equivalent stress in the pipe wall: a) as-welded, b) during an axial load of 182 $\mathrm{MPa}$ (outer surface), c) after an axial load of $182 \mathrm{MPa}, \mathrm{d}$ ) during an axial load of $337 \mathrm{MPa}$ (outer surface), e) after an axial load of $337 \mathrm{MPa}$ 


\section{Summary and Conclusions}

Residual stress relaxation in girth-welded steel pipes subjected to quasi-static tensile load stresses due to bending has been investigated using both X-ray and neutron diffraction. The main conclusions are summarized in the following:

- Tensile load stresses can lead to significant residual stress relaxation, which is most distinct at the weld root and at intermediate distances from the weld centerline. The higher the load stress, the more pronounced is the relaxation effect.

- Residual stress relaxation depends on the magnitude and direction of both load stress and residual stress. Therefore, a multiaxial analysis involving all stress components must be performed. It has been shown that the von Mises equivalent stress can be used to identify the locations where plastic yield and thus residual stress relaxation occurs, despite the simplifications that were assumed concerning stress concentration and structural hardening effects.

- However, changes in the residual stress state were also observed in areas where the equivalent stress did not reach the yield stress. This can be attributed to a redistribution of the residual stresses as the equilibrium of forces and moments must be satisfied.

- Changes in the residual stress distribution were observed both parallel to the load stress, i.e. in axial direction, and perpendicular to it, i.e. in hoop direction. The radial residual stress component, exhibiting relatively low values, was not affected.

- In general, the findings on the surfaces obtained by XRD and the results of the ND measurements in the pipe wall agree well. An exception to this is the residual stress state close to the weld root. Here, the XRD measurements on the inner surface of pipe sections yield different results than the ND measurements on intact pipes for both the original residual stresses after welding, see also [19], and the residual stress state after loading. In both cases, the ND measurements prove that the highest axial and hoop residual stresses occur in the weld metal or at the weld root notch, whereas the XRD measurements underestimate these stresses due to a relaxation effect occurring during the sectioning process. Moreover, the weld root geometry may affect the XRD measurements. Thus, ND measurements provide useful complementary information regarding the residual stresses in pipes.

- Due to stress concentration, the weld root notch is a potential location of fatigue crack initiation. Since the tensile residual stresses that were found there after welding can adversely affect both crack initiation and crack propagation, intentional overloading, i.e. applying a higher load stress than during service, can be used to improve the fatigue performance. Thereby, the tensile residual stresses are reduced by a higher amount than it would be the case due the load stress during regular service, thus resulting in a lower total stress.

The results of this study concerning the relaxation of residual stresses can be used to discuss their influence on the fatigue performance of girth-welded pipes, which will be the subject of future work.

\section{Acknowledgement}

This work was supported by the German Federal Ministry for Economic Affairs and Energy within the program for promoting the Industrial Collective Research (IGF), IGF No. 17.619N, on the basis of a decision of the German parliament.

A portion of this research used resources at the High Flux Isotope Reactor, a DOE Office of Science User Facility operated by the Oak Ridge National Laboratory. The assistance of P.A. Cornwell with the strain mapping experiments is gratefully acknowledged.

\section{References}

[1] Hobbacher AF (2016) Recommendations for Fatigue Design of Welded Joints and Components, 2nd edn. Springer, Heidelberg

[2] Vöhringer O (1987) Relaxation of residual stresses by annealing or mechanical treatment. In: Niku-Lari A (ed) Advances in surface treatments, Vol 4, International guidebook on residual stresses, Pergamon Press, Oxford, pp 367-396

[3] Amirat A, Mohamed-Chateauneuf A, Chaoui K (2006) Reliability assessment of underground pipelines under the combined effect of active corrosion and residual stress. Int $\mathrm{J}$ Pres Ves Pip 83:107-117

[4] McClung RC (2007) A literature survey on the stability and significance of residual stresses during fatigue. Fatigue Fract Eng M 30:173-205 
[5] lida K, Yamamoto S, Takanashi M. (1997) Residual stress relaxation by reversed loading. Weld World 39: 138-144

[6] lida K, Takanashi M. (1998) Relaxation of welding residual stresses by reversed and repeated loadings. Weld World 41: 314-327

[7] Takanashi M, Kamata K, Kunihiro I (2000) Relaxation behavior of welding residual stresses by fatigue loading in smooth longitudinal butt welded joints. Weld World 44:28-34

[8] Nitschke-Pagel T, Wohlfahrt H (2000) Residual stress relaxation in welded high strength steels under different loading conditions. In: Proceedings of the 6th International Conference on Residual Stresses: ICRS-6, Oxford, UK, pp 1495-1502

[9] Lachmann C, Nitschke-Pagel T, Wohlfahrt H (2000) Characterisation of residual stress relaxation in fatigue loaded welded joints by $\mathrm{x}$-ray diffraction and barkhausen noise method. Mater Sci Forum 347:374-379

[10] Han S, Lee T, Shin B (2002) Residual stress relaxation of welded steel components under cyclic load. Mater Technol 73:414-420

[11] Farajian M (2013) Welding residual stress behavior under mechanical loading. Weld World 57:157-169

[12] Farajian M, Nitschke-Pagel T, Dilger K (2010) Mechanisms of residual stress relaxation and redistribution in welded high-strength steel specimens under mechanical loading. Weld World 54:366-374

[13] Hensel J, Nitschke-Pagel T, Dilger K (2016) Effects of residual stresses and compressive mean stresses on the fatigue strength of longitudinal fillet-welded gussets. Weld World 60:267-281

[14] Wohlfahrt H, Nitschke-Pagel T, Dilger K, Siegele D, Brand M, Sakkiettibutra J, Loose T (2012) Residual stress calculations and measurements - review and assessment of the IIW round robin results. Weld World 56:120-140

[15] Bouchard PJ (2007) Validated residual stress profiles for fracture assessments of stainless steel pipe girth welds. Int J Pres Ves Pip 84:195-222

[16] Song S, Dong P, Pei X (2015) A full-field residual stress estimation scheme for fitness-forservice assessment of pipe girth welds: Part I - Identification of key parameters. Int J Pres Ves Pip 126-127:58-70

[17] Hempel N, Nitschke-Pagel T, Dilger K (2014) Residual stresses in multi-pass butt-welded tubular joints. Adv Mat Res 996:488-493

[18] Hempel N, Nitschke-Pagel T, Dilger K (2015) Residual stresses in multi-pass butt-welded ferritic-pearlitic steel pipes. Weld World 59: 555-563

[19] Hempel N, Bunn JR, Nitschke-Pagel T, Payzant EA, Dilger K (2017) Residual stress analysis in girth-welded ferritic and austenitic steel pipes using neutron and X-ray diffraction. Materials Research Proceedings 2:229-234 (DOI 10.21741/9781945291173-39)

[20] Rachinger WA (1948) A Correction for the a1 a2 Doublet in the Measurement of Widths of Xray Diffraction Lines. J Sci Instrum 25(7): 254-255

[21] Savitzky A, Golay MJ (1964) Smoothing and differentiation of data by simplified least squares procedures. Anal chem 36(8):1627-1639

[22] Woo W, Em V, Hubbard CR, Lee HJ, Park KS (2011) Residual stress determination in a dissimilar weld overlay pipe by neutron diffraction. Mat Sci Eng A 528:8021-8027

[23] Hutchings MT, Withers PJ, Holden TM, Lorentzen T (2005) Introduction to the Characterization of Residual Stress by Neutron Diffraction. CRC Press, Boca Raton

[24] Bunn JR: Personal communication

[25] Seyffarth P, Fischer S, Scharff A (1991) Prediction of Weld Dates With Computer-Aided Weldware-System of University of Rostock. In: JOM-5: International Conference on the Joining of Materials, Helsingør, Denmark, pp 180-185 
[26] Hempel N, Nitschke-Pagel T, Dilger K (2016): Study on the near-surface residual stress state in butt-welded pipes of austenitic steel using X-ray diffraction. Weld World 60: 1169-1179 (DOI 10.1007/s40194-016-0378-9) 